\title{
Análise da intervenção antrópica no balneário Curva São Paulo em Teresina-PI
}

\author{
Analysis of the anthropic intervention at the Curva São Paulo bathing resort in \\ Teresina-PI
}

\author{
SOUSA $^{1}$, E. M. da S.; FERREIRA², E. A.; MORAES ${ }^{3}$, M. V. A. R. \\ erikasousa123@yahoo.com.br
}

\begin{abstract}
Resumo
O presente trabalho representa uma tentativa de análise das alterações da área do Balneário Curva São Paulo, localizado na zona sudeste da cidade de Teresina, capital do Estado do Piauí. O artigo tem o objetivo de identificar as principais alterações causadas pela intervenção antrópica na área de estudo ao longo do tempo, bem como propor novas formas de intervenção mais adequadas, utilizando como recursos metodológicos imagens de satélite retrospectivas adquiridas através do software gratuito Google Earth, fotografias retiradas pelos autores e relatos dos moradores das áreas circundantes ao Balneário Curva São Paulo. Onde foi possível concluir que a ação antrópica agiu desde a implantação do balneário, tanto no desmatamento das áreas verdes quanto na poluição das águas do Rio Poti.
\end{abstract}

Palavras-chave: Intervenções Antrópicas. Google Earth. Curva São Paulo.

\begin{abstract}
This paper is an attempt to analyze the changes in the area of the Curva São Paulo Bathing Resort, located in the southeastern region of the city of Teresina, which is the capital of Piauí. This paper aims to identify the main changes caused by antrophic intervention over time in the studied area. It also proposes new appropriate forms of intervention by using methodological resources as old pictures from satellite images acquired using the free Google Earth software, photos taken by the authors, and reports from residents of the surrounding areas of the Curva São Paulo Bathing Resort. In which, it was possible to conclude that human action has been present since the creation of the bathing resort that caused the deforestation of green areas and the pollution of the Poti River.
\end{abstract}

Keywords: Anthropic intervention. Google Earth. Curva São Paulo.

\section{INTRODUÇÃO}

A transformação do espaço natural como resultado das diversas atividades empreendidas pelo homem na sua interação com a natureza tem se tornado cada vez mais evidente nos últimos anos. Tais transformações têm reduzido gradualmente o caráter natural dos ambientes, o que os torna um fértil campo para pesquisas geográficas.

O processo de urbanização é uma realidade constatada mundialmente. Em todo o mundo este processo tem sido intenso, modificando rapidamente a dinâmica das cidades. No Brasil, esse fato iniciou-se em meados do século XX sob a influência de diversos fatores, como a migração rural-urbana e a explosão da industrialização nas grandes cidades, abordados anteriormente.

O modelo de desenvolvimento das sociedades humanas ao longo de sua história, e especialmente a partir da revolução industrial, tem sido agressivo e predatório aos ecossistemas, portanto insustentável e gerador de uma série de danos socioambientais, dentre os quais inúmeros riscos à saúde das populações silvestres e também humanas (CANO, 1989). 
O presente trabalho representa uma tentativa de análise das transformações causadas ao longo do tempo pela atividade antrópica no Balneário Curva São Paulo, localizado na cidade de Teresina, capital do Estado do Piauí. Para tal iniciativa, foram utilizadas imagens de satélite multitemporais do software Google Earth, comparadas com fotografias atuais retiradas pelos autores. A análise pretende servir ainda como parâmetro para as futuras intervenções a serem realizadas na área pesquisada.

Para a referida análise, iniciou-se com a discussão da evolução histórica da urbanização brasileira. Posteriormente observou-se os principais impactos ambientais gerados pelo crescimento urbano desordenado, fundamentando a análise da área de estudo e as conclusões elaboradas.

\section{METODOLOGIA}

Os materiais empregados para a realização da pesquisa constituíram-se de imagens de satélites multitemporais do Balneário Curva São Paulo adquiridas através do software Google Earth em diversos momentos da evolução histórica da área (imagens retrospectivas), imagens estas que foram comparadas entre si e com fotografias retiradas pelos próprios autores quando das visitas ao Balneário Curva São Paulo realizadas no decorrer do mês de junho de 2016.

O Google Earth consiste em um software gratuito de desenvolvimento e distribuição feita pelo Google Inc., tendo como objetivo representar tridimensionalmente o globo terrestre, através de um mosaico de fotografias realizadas via satélite. Tendo como base toda a sua funcionalidade, destaca-se que suas fotografias facilitam o desenvolvimento de trabalhos de cunho geográfico que prescindem da análise de uma extensa área do planeta. Como afirma Silva (2013):

Uma das principais funções observadas no uso do recurso do Google Earth é enquanto forma de análise geográfica no sentido de localização de determinados lugares e seus fenômenos cuja possibilidade de visitação se torna difícil por determinados fatores, como distância, dentre outros. Essa possibilidade de análise, porém, vai além de uma visão mais geral a nível continental ou regional, podendo se trabalhar aspectos mais particulares, como por exemplo, algumas especificidades de algum ponto de uma determinada cidade, ou alguma fronteira física.

Somados aos materiais acima descritos, foram utilizados fotografias e relatos cedidos pelos moradores das áreas circundantes ao Balneário Curva São Paulo.

O percurso metodológico para a realização da pesquisa teve início com a delimitação da área de estudo a partir da utilização do software Google Earth, delimitando-se a área de interesse para o presente trabalho. Em seguida, foram coletadas as imagens de satélites multitemporais (2005 a 2015) disponíveis no software em questão, que serviriam como base para a análise das alterações 
antrópicas e naturais observadas no Balneário. A análise também lançou mão das fotografias retiradas pelos autores quando da visita à área de estudo após a sua delimitação. Por último, foram adquiridas as imagens disponibilizadas pelos moradores das áreas vizinhas ao Balneário, que também fundamentaram a análise a seguir.

\section{RESULTADOS E DISCUSSÃO}

Para um melhor entendimento é necessário, primeiramente, o conhecimento dos conceitos de impacto ambiental, tanto na legislação brasileira quanto na literatura especializada.

Para Guerra e Cunha (2001), impacto ambiental é o processo de mudança ocorrido a partir da intervenção antrópica no ambiente, "é a relação entre sociedade e natureza que se transforma diferencial e dinamicamente".

Segundo os próprios autores, este processo se realiza em movimento permanente, fazendo com que ele seja o efeito e a causa de novos impactos ambientais:

O impacto ambiental não é, obviamente, só o resultado (de uma determinada ação realizada sobre o ambiente): é relação (de mudanças sociais e ecológicas em movimento). Se impacto ambiental é, portanto, movimento o tempo todo, ao fixar impacto ambiental ou ao retratá-lo em suas pesquisas o cientista está analisando um estágio do movimento que continua.

O impacto ambiental pode ser de caráter positivo ou negativo, apesar de ser comum sua utilização no sentido negativo. No caso da urbanização, a maioria dos impactos positivos está associada aos benefícios sociais e econômicos, enquanto que os aspectos ecológicos ficam com a maior carga de impactos negativos (MOLFI, 2009).

Embora possam ter diferentes magnitudes, os impactos ambientais negativos no meio urbano apresentam-se mais contundentes nas áreas ocupadas pelas classes sociais menos favorecidas, muito por que a distribuição destas se dá em espaços desvalorizados que, quase sempre, se situam em áreas de risco ambiental (GUERRA; CUNHA, 2001).

Com relação aos impactos provenientes do processo de urbanização, Mota (2003 p.53) aponta o solo, os recursos hídricos e a atmosfera como os fatores naturais mais suscetíveis à degradação com reflexos negativos sobre o clima, a fauna e a flora locais:

A ocupação de um ambiente natural, no processo de urbanização, geralmente ocorre com a remoção da cobertura vegetal. O desmatamento, quando feito de forma inadequada, resulta em vários impactos ambientais, tais como: modificações climáticas; danos à flora e à fauna; descobrimento do solo causando o incremento da erosão; remoção a camada fértil do solo, empobrecendo-o; assoreamento dos recursos hídricos; aumento do escoamento superficial da água e redução da infiltração; inundações. 
De acordo com Spirn (1995), no processo de urbanização e manutenção das cidades, as ações antrópicas passam a ser verdadeiros agentes geológicos que alteram constantemente a topografia através de cortes, aterros e dragagem dos cursos d'água e, ainda, modificam o relacionamento da superfície do solo com o substrato rochoso, por meio das impermeabilizações provocadas pela pavimentação das vias e pelas construções prediais e, também, pela escavação do subsolo para a implantação de poços, fundações e túneis.

Quanto à água a pesquisadora destaca:

Água poluída, enchentes e secas castigam a cidade. Rios turvos, carregados de esgoto, sedimento, lixo e outros produtos químicos fluem através da cidade, um caldo sujo do qual muitas cidades retiram sua água para beber. Em alguns anos, só as enchentes serão responsáveis por danos materiais nos Estados Unidos do que qualquer outro fenômeno natural, ainda que a seca esteja se transformando num fenômeno urbano cada vez mais comum. Todas as cidades, mesmo aquelas em climas úmidos, logo se defrontam com a perda do seu mais precioso recurso - um suprimento abundante de água não contaminada (SPIRN, 1995 p.145).

O Balneário Curva São Paulo está situado no bairro São Sebastião, zona sudeste da cidade de Teresina-PI, desde 1993. Criado a partir da implementação do Residencial São Paulo, conjunto habitacional da Prefeitura que teve como objetivo proporcionar moradia para uma parcela da população carente nesse aspecto. Com o conjunto habitacional, a movimentação na região aumentou, chamando atenção para a área na margem do rio que podia ser utilizada para a recreação, como é observado na Figura 1.

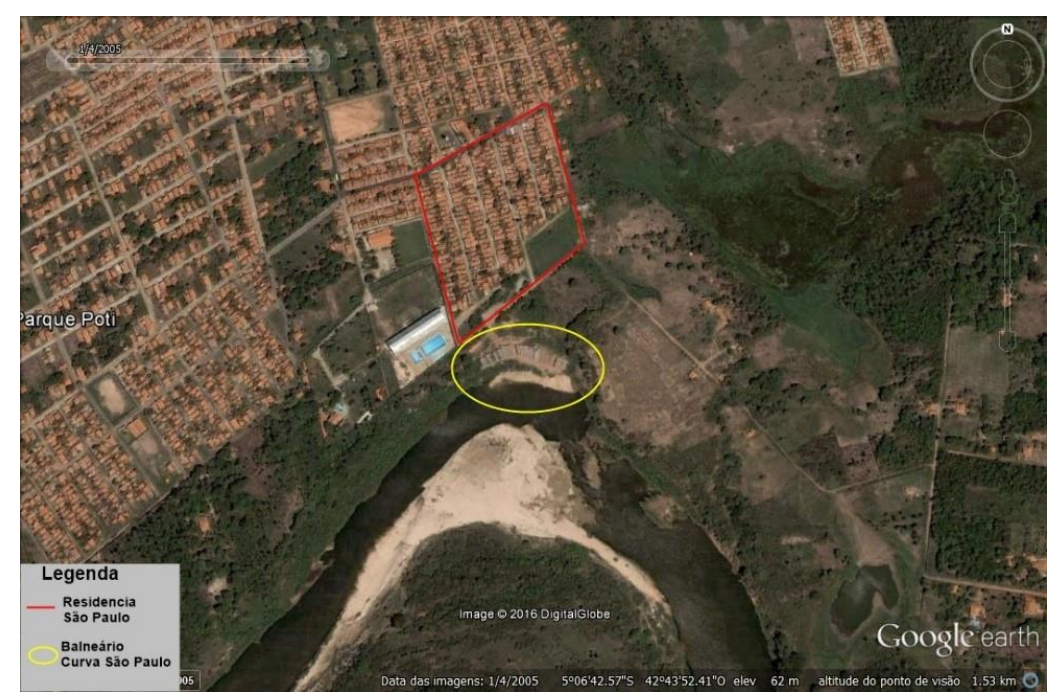

Figura 1 - Vista aérea da localização do Residencial São Paulo ocupada e do Balneário antes da estruturação da região Fonte: Google Earth (1/04/2005) 
Tendo como um atrativo para vendedores (em sua maior parte moradores da região), o balneário Curva São Paulo, no início de suas atividades, eram estabelecidas barracas de madeiras, cobertas com palhas para a comercialização de comidas e bebidas, mesmo sem infraestrutura básica (água encanada, energia elétrica e com banheiros improvisados), muitas famílias tiravam o seu sustento das atividades exercidas no Balneário, tendo ele como única fonte de renda. Com a quantidade elevada da população que frequentava a margem do rio Poti nos fins de semana, e levando em consideração às precárias condições das barracas estabelecidas, ocorria um grande impacto ambiental nessa área do rio Poti.

Como citado anteriormente, a aglomeração de pessoas, o lixo produzido, os dejetos que derivavam dos banheiros improvisados, assim como o despejo de todo o esgoto da região adjacente do balneário, os impactos negativos ao espaço natural eram nítidos, fazendo com que a poluição das águas do rio tornasse nítida para os olhos dos pesquisadores, mas camuflada para a maior parcela da população. Nos anos iniciais de atividade recreativa, apesar da preocupação com as questões ambientais já serem abordadas nas escolas e nos veículos de comunicação, via-se tudo como algo passageiro e não permanente, como afirmam os relatos de moradores antigos da região em conversas informais que corroboraram com as hipóteses levantadas.

Por conta das pressões dos donos das barracas por melhores condições de trabalho e pela a falta de ambientes destinados ao lazer, em 2006, o poder público municipal desenvolveu um projeto, que consistia em obras para estruturação do balneário, proporcionando a adequação do espaço para atividade comercial e um mecanismo de segurança para os frequentadores, tornando-se assim um ponto turístico da cidade (Figura 2).

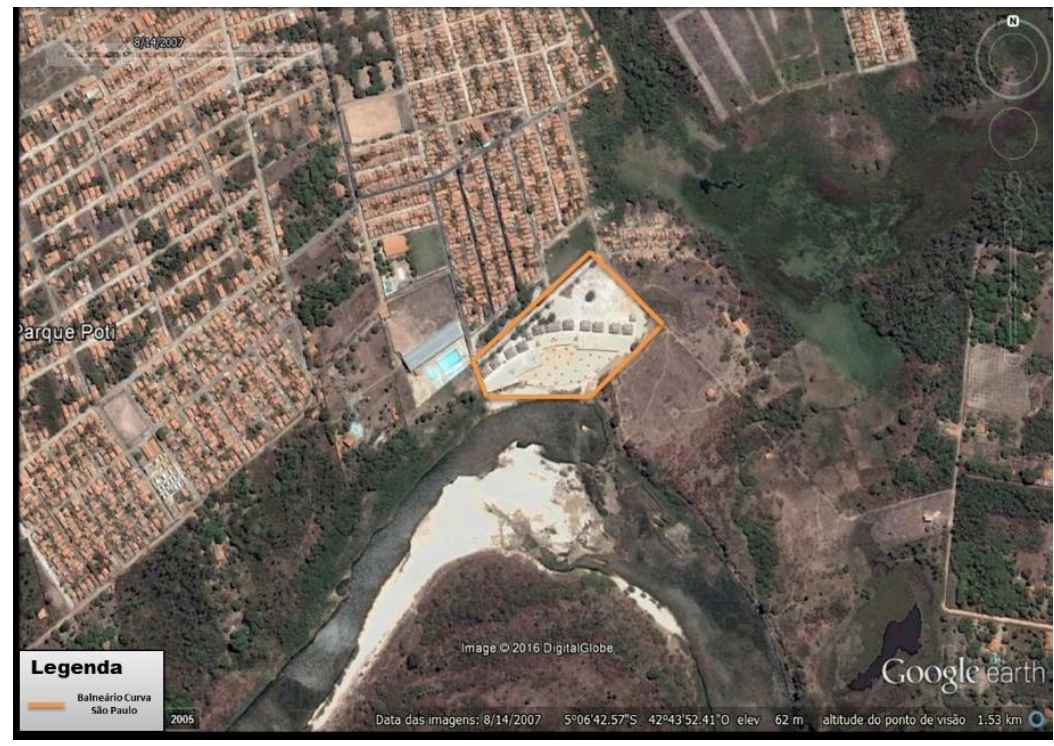

Figura 2 - Vista aérea do Balneário Curva São Paulo após reforma

Fonte: Google Earth (14/08/2007) 
O Plano de Controle Ambiental do balneário, o denominou de Parque Ambiental Curva do São Paulo, e tem como principal objetivo manter a área verde que circunda a margem do rio, tendo como segundo plano a estruturação do balneário:

criar mecanismos de proteção ambiental para que a área verde da Curva do São Paulo - Parque Ambiental Curva do São Paulo - desempenhe melhor suas funções de caráter ecológico, paisagístico e recreativo, e assim, propiciar a melhoria da qualidade estética, funcional e ambiental da área (TERESINA, 2006. p. 5).

Mas como foi notado essa preocupação ambiental manteve-se apenas nos documentos. Reflexo disso, é o despejo irregular do esgoto das casas próximas mesmo após a reforma da Curva São Paulo.

Observou-se também a porção de mata virgem que foi desmatada para a construção do estacionamento da mesma, segundo os moradores da região, essa ação causou um desequilíbrio ambiental quando se refere aos animais que habitava a área verde, onde os predadores naturais dos anfíbios adentraram para outras regiões, fazendo com que a população de sapos aumentasse.

Com os sedimentos sendo depositados na parte côncava da curva que o rio faz, forma-se uma praia que facilitou a ocupação da margem para a utilização de recreação e comércio. A deposição de sedimentos na parte côncava, visualizada na área do balneário, parece estar associada ao controle da direção e força do fluxo d'água, imposto pelo afloramento rochoso localizado à montante do balneário, nos períodos em que a vazão diminui em função do período de estiagem, atualmente este afloramento rochoso é encontrado fora do rio, pois o canal fluvial mudou sua configuração, é possível observar essas colocações que ocorreram durante os anos na Figura 3, em que o comparativo apresenta duas facetas, sendo a imagem A do período de estiagem em 2005, e B, imagem mais recente do período de estiagem em 2013.

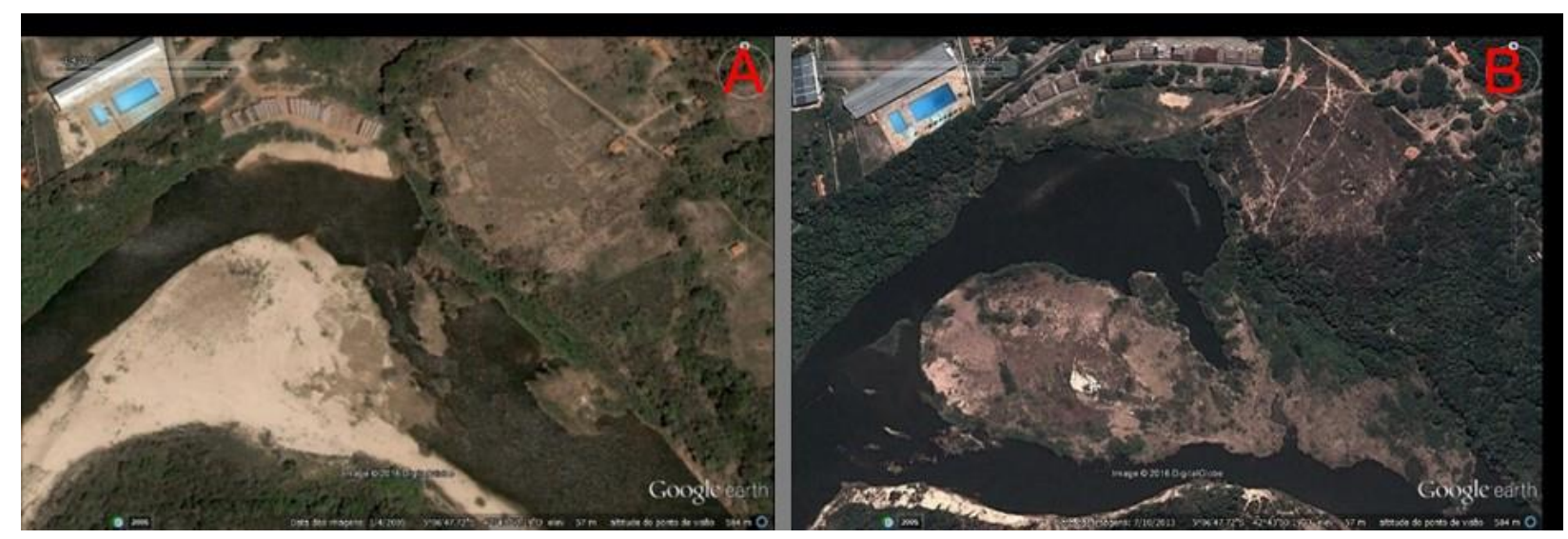

Figura 3 - Imagem comparativa no decorrer dos anos, 2005 e 2013

Fonte: Google Earth (A: 01/04/2005 - B: 07/10/2013) 
É notável o momento de maior vasão do rio é no período chuvoso, fazendo com que a deposição de sedimentos seja maior, entretanto só é possível notar essa característica quando o volume das águas baixa.

Essa mudança deve-se, principalmente, pela a ocorrência das enchentes nos anos de 2008 e 2009, sendo esta última, atingindo as casas do Residencial São Paulo, causando danos estruturais para o balneário e para as residências adjacentes. Como é possível ver na Figura 4, a imagem B (2013), apresenta a nova configuração, onde o rio procura a retilineaidade, de seu percurso, como afirma Chritofoletti (1980), em setores dos canais fluviais que apresentam curvatura, têm-se a deposição de sedimentos na margem convexa (local de menor velocidade) e escavação na margem côncava (local de maior velocidade da corrente).

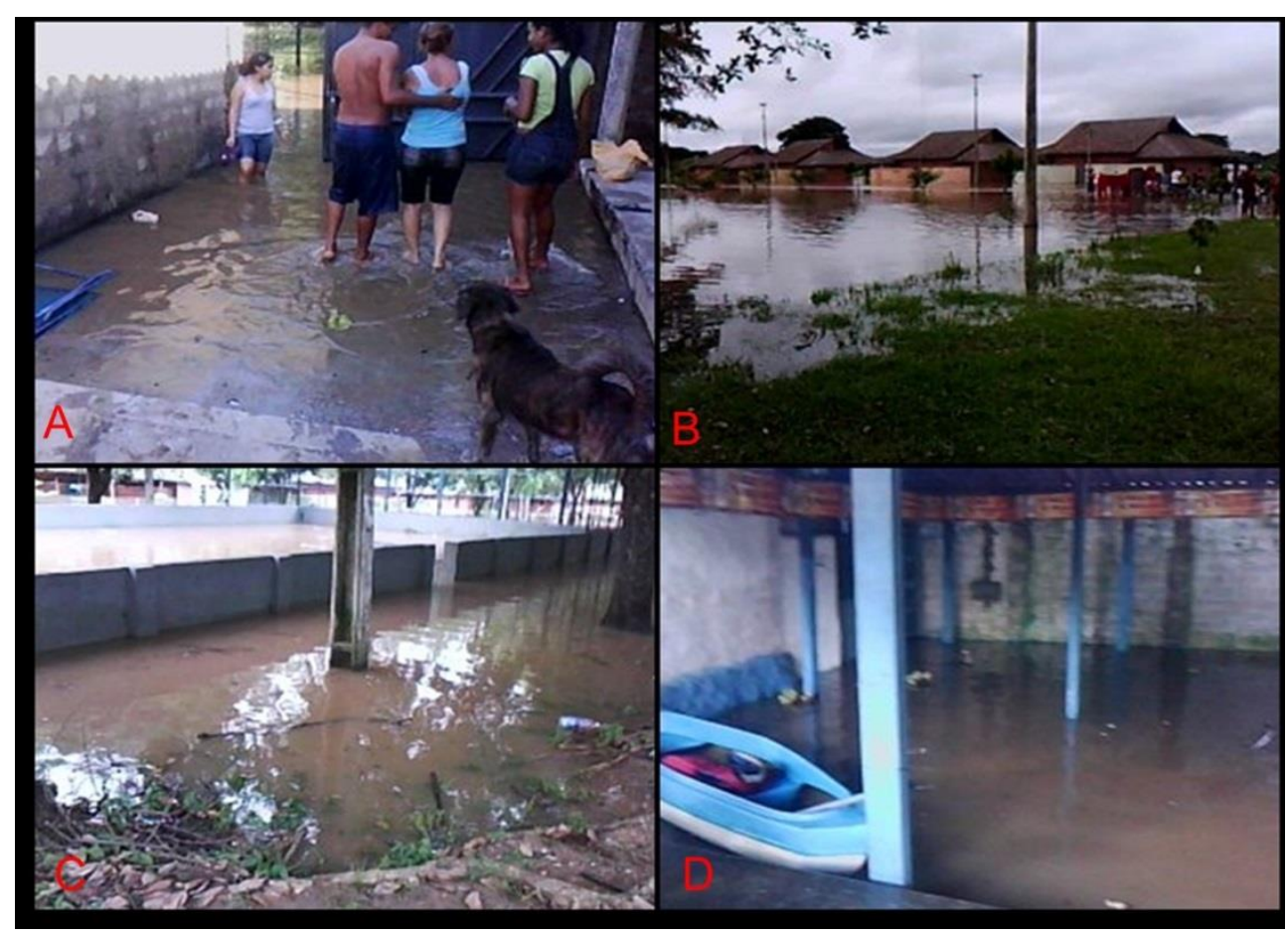

Figura 4 - Moradores e barraqueiros na enchente de 2009

Fonte: Moradores da região, 2009

Ao analisar a figura 4 podemos encontrar imagens dos danos estruturais na região do Residencial São Paulo. Na imagem A, mostra o avanço da água em uma casa que se encontra em frente do balneário. O campo de futebol foi completamente coberto pela a água do rio, como podemos ver na imagem $B$, fato este que ocorreu também com a praça do residencial. Alguns pequenos estabelecimentos comerciais foram atingidos pela a enchente, como é possível ver na imagem D.

Todos esses danos nas estruturas da Curva São Paulo foram parcialmente mascarados pelo os barraqueiros, pois o poder público, segundo os barraqueiros, resolveu não influenciar mais 
estruturalmente nos danos que possam gerar um gasto maior. Os danos que as casas da população do Residencial São Paulo sofreram, foram sendo estabelecidos a normalidade com o passar dos anos, mas não foi oferecida nenhuma ajuda financeira por parte da prefeitura.

Atualmente o contingente de pessoas que frequentam o balneário para os fins de lazer é menor ao comparar com os anos antes das enchentes, fato que ocasionou a desistência de muitos barraqueiros. Os barraqueiros atribuem a culpa não somente as inundações, mas principalmente a propaganda negativa que as mídias locais fizeram sobre as perspectivas de revitalização.

\section{CONSIDERAÇÕES FINAIS}

Diante do que foi apresentado, é perceptível a importância das atividades econômicas que o balneário Curva São Paulo trouxe para a cidade como um todo, levando a considerar que as temperaturas elevadas que o município apresenta são de grande atrativo para atividades que ocorrem próximo a água. Porém, ao analisar a mudança ocorrida com a implantação do balneário, alterando o ambiente a partir, principalmente, dá relação entre sociedade natureza, temos que admitir que o balneário tornou-se um grande feitor de impactos ambientais.

Desde o início da instalação dessas atividades na margem do rio, problemáticas ambientais negativas foram tornando-se cada vez mais aparente na região, como a presença do lixo e do esgoto gerado pela a ação humana na região que fez com a qualidade da água do rio Poti diminuísse, desde a sua implantação. Após a estruturação do balneário a ação antrópica foi mais evidente, sendo destacado o desmatamento de áreas verdes, causando desequilíbrio ecológico na área de estudo.

É preciso enaltecer o descaso com o objetivo principal do Plano de Controle Ambiental apresentado na época de formulação do projeto, subvalorizando o nome de Parque Ambiental Curva do São Paulo, provavelmente, tendo um caráter e sendo reconhecido como um parque ambiental todo o recorte da área estudada teria suas deficiências ambientais amenizada, ou até mesmo sessadas.

\section{REFERÊNCIAS}

CANO, W. Urbanização: sua crise e revisão de seu planejamento. Revista de Economia Política, v. 9, n. 1, jan./mar.1989.

CHRISTOFOLETTI, Antonio. Geomorfologia. 2. ed. São Paulo: Edgard Blucher, 1980.

GUERRA, Antonio J. ; CUNHA, Sandra B. Impactos ambientais urbanos no Brasil. Rio de Janeiro: Bertrand Brasil, 2001. 
MOLFI, Paulo Roberto. A urbanização e os impactos ambientais em Palmas: o caso do Jardim Aureny III. 2009. 130 f. Dissertação (Mestrado em Arquitetura e Urbanismo) - Universidade de Brasília, Brasília-DF. 2009.

MOTA, Suetônio. Urbanização e meio ambiente. Rio de Janeiro: Associação Brasileira de Engenharia Sanitária, 2003.

SILVA, A.; ASSIS NETO, A.; OLIVEIRA, L. Revista Equador (UFPI), Vol.2, № 2, p. 173 -188 (Julho/Dezembro, 2013).

SPIRN, Anne W. O jardim de granito: a natureza no desenho da cidade. São Paulo: 1995.

TERESINA. Plano de Controle Ambiental (PCA). Prefeitura Municipal de Teresina: Superintendência de Desenvolvimento Urbano e Meio Ambiente- SDU/Sudeste, 2006.

\section{AGRADECIMENTOS}

Agradeço em primeiro lugar a Deus que iluminou o meu caminho durante a realização desse trabalho.

À professora Maria Valdirene, pela paciência na orientação e incentivo que tornaram possível a conclusão deste artigo.

Aos meus amigos e companheiros de curso que sempre dão força em qualquer empreitada, ajudando a tornar tudo possível.

Recebido em: 14/08/2016

Aceito para publicação em: 01/10/2016 